\title{
Manic depressive illness in a founder population
}

\author{
Evelyne Heyer ${ }^{1,2}$, Bruno Toupance ${ }^{1,2}$, Cesare Perri ${ }^{3}$, Ornella De Vito ${ }^{3}$, Jean-François \\ Foncin $^{*}, 4$ and Amalia Cecilia Bruni ${ }^{3}$
}

\author{
${ }^{1}$ Laboratoire d'Anthropologie Biologique, Museum National d'Histoire Naturelle, CNRS FRE2292, France; ${ }^{2}$ Université \\ Paris 7, Denis Diderot, Paris, France; ${ }^{3}$ Centro Regionale di Neurogenetica, AS 6, Lamezia Terme, Calabria, Italy; \\ ${ }^{4}$ Laboratoire de Neurohistologie, Ecole Pratique des Hautes Etudes, Brie Comte Robert, France
}

Manic depressive illness (MDI) segregates within a founder population originating from $S$, a mountain village in Southern Italy. Identity by descent of affected persons cannot be established by direct genealogical methods. A 56000 persons family reconstruction data base encompasses the whole population of $S$ in the 17th and 18th centuries, and part of the population of $S$ and neighbouring villages in the 19th and 20th centuries. We selected $10 \mathrm{MDI}$ probands who were members of the $S$ population and not evident close relatives of each other. A total of 10 other MDI probands not evidently related to the $S$ population formed a first control group. A second control group was formed with 10 not closely related persons originating within the $S$ population. We determined the founders common ancestors to all the probands of one group but not ancestors to the probands of other groups, and computed the genetic contribution of each founder to each proband. The distance between probands in the S MDI group was calculated with respect to all the founders. In all, 17 founders present in the ascendancy of all individuals of the S MDI group are not present in the ascendancy of the control groups: MDI patients are derived from a subpopulation within S. Two S MDI probands are far from one another in respect of the 'nonspecific' founders, but are very close in respect of the specific founders: a putative MDI trait originated from specific founders of the MDI subpopulation, and hence is identical by descent in the $S$ population. European Journal of Human Genetics (2003) 11, 597-602. doi:10.1038/sj.ejhg.5201001

Keywords: manic depressive illness; psychiatric genetics; human population genetics; founder populations

\section{Introduction}

There is long-standing evidence ${ }^{1}$ for the prevalence of genetic factors in the causation of manic-depressive illness (MDI). In spite of this, it has not been possible up to now to identify unequivocally loci, genes or mutations operative in that direction. Many studies gave negative results; on the other hand, apparently solid positive results could not be replicated in different settings or became negative when extended within the same kindred. ${ }^{2}$ Two, not mutually

*Correspondence: Professor J-F Foncin, Laboratoire de Neurohistologie, 47 rue Général Leclerc, F77170 Brie Comte Robert, France. Tel/Fax: +33 1 60625102 ;

E-mail: j.f.foncin@wanadoo.fr

Received 15 May 2001; revised 9 December 2002; accepted 27 February 2003 exclusive, explanations have been forwarded to explain this state of affairs. The 'complex disease' model proposes that individual instances of MDI are caused by a number of factors, both genetic ('MDI is polygenic') and environmental, and that the design and power of previous studies were not adapted to that situation. The 'heterogeneity' model proposes that, while individual instances of MDI may be due essentially to a single genetic factor, any grouping of instances of MDI is bound to incorporate cases with various causations ('MDI is multigenic'), making linkage studies impossible and severely diminishing the power of association studies - not to speak of the fundamental limitations of association studies as a tool for the identification of causes. A factor of heterogeneity within mood disorders is that current empirical categorisations such as DSM IV ${ }^{3}$ were not designed to relate to causes, 
and in fact specifically exclude the consideration of causes for major psychiatric categories. It is not known whether various instances of mood disorders: bipolar I, bipolar II, severe depression, schizoaffective disorder, to name a few, may be due to the same cause; conversely, it is highly probable that any of them may be due to various causes.

The study of founder populations might be a way to obviate the difficulties arising from genetic heterogeneity: if founders are few, chances are increased for only one of them having introduced a genetic factor causing MDI into the population, and hence for severe mood disorders to be genetically homogenous within that population. We had studied earlier a founder population (thereafter the $S$ population) that harbours a form of early onset familial Alzheimer's disease (FAD) ${ }^{4}$ results obtained from that population were instrumental in the cloning of the preseniline 1 gene. ${ }^{5}$ We later found within the $S$ population a number of persons apparently affected with severe forms of mood disorders, with instances of apparent Mendelian transmission at the nuclear family level. ${ }^{6}$ However, Mendelian methods that we had used to establish the identity by descent at an FAD locus of patients affected with early onset FAD were not suitable for MDI: ${ }^{7,8}$ the definition of a relevant phenotype is imprecise; the mode of transmission is ill-defined; penetrance is unknown, but possibly low. In order to by-pass these difficulties, we decided to test with population genetics methods the possible applicability of data from the MDI subpopulation within the $S$ population to problems relevant to the molecular genetics of MDI.

\section{Material and methods}

1. The $S$ population is the population of the village of $S \ldots$, currently 3838 inhabitants, situated in a mountain setting in Calabria, a region of Southern Italy (Figure 1) numbering now about 180000 . There is historical evidence ${ }^{9}$ that the $S$ village has been founded in the 13th century by about five nuclear families that moved from a village on the other side of the mountains in consequence of an earthquake. Surname repartition indicates that subsequent immigration has been low. Population growth appears to have been slow until the 16th century. Successively, families migrated from $\mathrm{S}$... into the vicinity to form small communities that are still administratively dependent of the village of S... . More recently, from the 17 th century onwards, some families migrated from S... towards the neighbouring plains, mainly to the town of N... (current population about 80000 inhabitants), where the abovementioned FAD kindred ('family $\mathrm{N}$ ') was first identified in 1973.

2. We continued the incorporation into a computerised database of reconstructed families on the basis of municipal records of births, marriages and deaths ('stato civile',

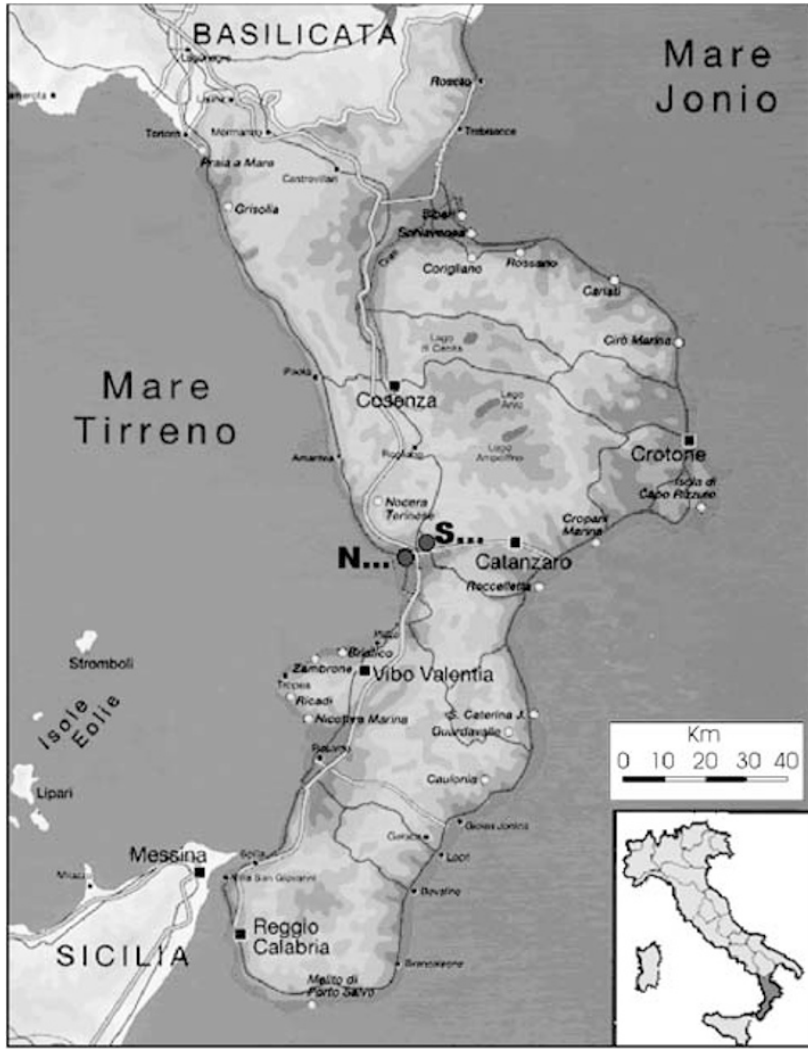

Figure 1 Calabria region; $\mathrm{N}$ : town of $\mathrm{N}$; S: village of $\mathrm{S}$.

from 1809 on), of parish records of baptisms, marriages and burials (about complete from 1630 on in the village of S..., with indications about early 17 th and late 16 th centuries). We used also family reconstructions that had already partially been accomplished by parish priests as part of their interest in their flock ('Status Animarum'), and later by municipal authorities for police and tax reasons ('Anagrafe'). For the earliest period, we remedied some deficiencies of the parish records through the study of notary archives. Coverage of the 17th and 18th centuries is complete regarding the village of $\mathrm{S}$...; coverage of the 19th and 20th centuries in N..., in S... and, to lesser extent, in other villages, is not systematic, having been achieved through (as far as possible unbiased) tracing of the ancestors of probands for various neuropsychiatric diseases, notably FAD, and through spot use of municipal records and Status Animarum covering various periods of time. Total number of persons currently entered into the database is 56000 , among whom 984 are founders, that is, persons whose parents are not present in the database, mainly because they lived before the start of parish records (1606) or because single parish acts were lacking. There is circumstantial evidence $^{9}$ that these parents lived in the village of S. In the 19-20th centuries some people moved to $\mathrm{S}$... from other villages. Their parents are not present in 
the database but they are not considered as founders of the $\mathrm{S}$ population.

3. We inspected, after written permission granted by the administrator in charge of the Local Health Agency (ASL) covering the area under study, the 2500 records, concerning the period from 1976 to 1996, of the public Psychiatric Department of the N... Hospital. The study was conducted in agreement with Italian no. 675 privacy law, which allows consultation of medical records by third parties for scientific purposes. The Department serves a territory of about 200000 people comprising the town of $\mathrm{N}$... and neighbouring villages in the plains and in the mountains, including $\mathrm{S}$.... No other psychiatric facility exists in the territory and there are no distinction between poor or rich families concerning the access to psychiatric primary care.

We first selected 95 probands as being possibly affected with MDI on the basis of the interpretation of the complete record of the patients and successively we personally (CP) interviewed patients that were contacted through their family physician. Patients were informed of the purpose of the study and gave their written consent. DSM IV classification of the relevant episode was: mood disorder in 70 instances; psychotic disorder,18; disorder due to alcohol, 2; anxiety disorder, 2; personality disorder, 2; somatisation disorder, 1.

To ascertain whether these MDI patients have some common ancestors and to calculate the identity by descent, we automatically traced the ancestry of these 95 probands (41 males, 54 females) and visually inspected the corresponding graphic pedigrees.

Within the group defined in this way, we selected 10 MDI probands (hereafter the P group) on the basis of being in descent of members of the $S$ population, and of not being evident close relatives of each other. In all, 10 other MDI probands (the $\mathrm{M}$ group), originating from other villages or from the town of $\mathrm{N}$..., were not evidently related to the $\mathrm{S}$ population and formed a first control group. A second control group (the A group) was formed with 10 not closely related patients affected by FAD, who, as indicated in the Introduction section, were already known to originate within the $\mathrm{S}$ population and not to be closely related to MDI patients.

We would control in this manner both for the specificity of the S population and for possible effects of MDI on the population structure.

4. Genetic analysis of the subpopulations: first, for each founder we counted in each group the number of probands this founder is an ancestor of. This allows us to identify which founders are common ancestors to all the probands of one group but not ancestors to the probands of other groups. Second, we computed the genetic contribution ${ }^{10}$ of each founder to each proband.

Third, the distance between two probands in the P group was calculated as the sum on the founders of the square differences of his/her genetic contribution to the two probands. The distance was computed for all the founders and for the founders specific to MDI probands. These distance matrices have been represented by standard principal component analysis.

\section{Results}

(1) Founders are distributed according to the number of probands in each group they have in their descent. This distribution of the founders to the three groups ( $\mathrm{P}, \mathrm{M}$ and A) defined above is shown pairwise by Tables $1-3$.

Table 1 compares group $\mathrm{P}$ (MDI in population S) with group A (FAD in population S). In all, 17 founders are present in the ascendancy of all individuals of the $\mathrm{P}$ group and are not present in the ascendancy of the A group; on the opposite, all the common founders of the A group are present as founders of the $\mathrm{P}$ group.

A provisional conclusion is that MDI patients are derived from a relatively independent subpopulation within $\mathrm{S}$, whereas FAD patients, while being all in descent of an identified individual living in $S_{\ldots} \ldots$ at the end of the 17 th century, ${ }^{11}$ are part of the general $S$ population.

Table 2 compares group A with group M (MDI in the plains population). No founder is common to more than

Table 1 Distribution of founders according to the number of probands in their descent within groups $\mathrm{P}$ and $\mathrm{A}$

\begin{tabular}{|c|c|c|c|c|c|c|c|c|c|c|c|c|c|}
\hline & \multicolumn{13}{|c|}{ Group P Number of probands } \\
\hline & Total & 311 & 260 & 89 & 85 & 60 & 60 & 20 & 23 & 29 & 30 & 17 & 984 \\
\hline
\end{tabular}


Table 2 Distribution of founders according to the number of probands in their descent within groups $M$ and $\mathrm{A}$

\begin{tabular}{|c|c|c|c|c|c|}
\hline & & \multicolumn{4}{|c|}{ Group M Number of probands } \\
\hline & & 0 & 1 & 2 & Total \\
\hline \multirow{8}{*}{$\begin{array}{l}\text { Group A Number of } \\
\text { probands }\end{array}$} & 0 & 659 & 201 & 20 & 880 \\
\hline & 1 & 66 & & & 66 \\
\hline & 3 & 4 & & & 4 \\
\hline & 4 & 15 & & & 15 \\
\hline & 8 & & 6 & & 6 \\
\hline & 9 & 2 & 3 & & 5 \\
\hline & 10 & 8 & & & 8 \\
\hline & Total & 754 & 210 & 20 & 984 \\
\hline
\end{tabular}

Table 3 Distribution of founders according to the number of probands in their descent within groups $P$ and $M$

\begin{tabular}{|c|c|c|c|c|c|}
\hline & & \multicolumn{4}{|c|}{ Group M Number of probands } \\
\hline & & 0 & 1 & 2 & Total \\
\hline \multirow{12}{*}{$\begin{array}{l}\text { Group P Number } \\
\text { of probands }\end{array}$} & 0 & 87 & 204 & 20 & 311 \\
\hline & 1 & 260 & \multirow{5}{*}{2} & & 260 \\
\hline & 2 & 87 & & & 89 \\
\hline & 3 & 85 & & & 85 \\
\hline & 4 & 60 & & & 60 \\
\hline & 5 & 60 & & & 60 \\
\hline & 6 & 19 & \multirow[t]{3}{*}{1} & & 20 \\
\hline & 7 & 23 & & & 23 \\
\hline & 8 & 29 & & & 29 \\
\hline & 9 & 27 & \multirow[t]{2}{*}{3} & & 30 \\
\hline & 10 & 17 & & & 17 \\
\hline & Total & 754 & 210 & 20 & 984 \\
\hline
\end{tabular}

two members of group $\mathrm{M}$, indicating the heterogeneity of that group and its independence from the $S$... population.

Table 3 compares group $P$ with group $M$. The 17 founders who are common to members of group $\mathrm{P}$ are not found as ascendants of group $\mathrm{M}$ members, indicating the genetic independence of group $\mathrm{P}$ with respect to group $\mathrm{M}$.

It is deduced from these results that if there is a common genetic factor for MDI within population $\mathrm{S}$, this factor is inherited from (at least) one of the 17 'specific' founders common to members of group P.

The 17 specific founders of the P group are all originating from S...population and are distant from living MDI patients about 15/16 generations. Founders are grouped in six couples (Figure 2) married from the mid-1500 to the mid-1600.

(2) Study of the genetic contribution of founders to group P individuals. Figure 3 shows the repartition of group
$\mathrm{P}$ individuals on the two first principal components according to the genetic contribution of the 'P-specific' founders. Genetic proximity of group $\mathrm{P}$ individuals to other members of that group, however, may be due to recent coalescence and not to the 'P-specific' contribution. To control for that factor, we calculated the genetic proximity of the $10 \mathrm{P}$ individuals, relative to the whole group of founders. The result is shown in Figure 4. Distances based on Kinship coefficients yield the same representation.

Comparison of the two representations shows that patients identified by P3, P4, P6 and P7 are indeed closely related on both counts (although this fact was not apparent on inspection of the graphic transcription of pedigrees). P1 and P9 patients are close according to one axis, but not according to the other. P2 and, more so, P5, are globally close to the $\mathrm{P} 3-\mathrm{P} 7$ subgroups, while receiving distinct contributions from the 'specific' founders. On the opposite, P8 and P10 are genetically close regarding the 17 'specific' founders, but display a different profile regarding their general genetic pattern.

\section{Discussion}

We deliberately choose the concept of MDI to represent the object of our studies. This concept originated with Kraepelin ${ }^{12}$ more than a century ago, as an example of the general 'Krankheitbegriff' of that author, that is, of the conception according to which mental disorders are expressions of diseases (illnesses) in the traditional, medical sense of the word: entities that are ultimately to be defined by their cause or agent, although provisionally, so to speak, a purely syndromic definition has often to be used. According to Kraepelin, MDI was an 'endogenous psychosis', that is, a condition due to factors within the patient, and not to external causes; at that time, of course, although MDI was known to 'run in families', the concept of genetic diseases did not exist. The Kraepelin concept is in line with our ultimate purpose, which is the isolation of (genetic) causes of instances within a class of psychiatric manifestations, and has been used in recent genetic studies. ${ }^{13}$ The absence of generally accepted criteria for MDI is not an obstacle barring the use of that concept for the purpose of the present study. We might as well define our object as 'the multifacetted severe mood disorder that segregates within population $\mathrm{S}^{\prime}$, subject to a posteriori confirmation of the homogeneity of the disease defined that way. In case of heterogeneity, this method could have been used to identify among probands an homogeneous subset.

A first indication of genetic homogeneity within 'population S MDI' is given by the results displayed in Table 1: within population S, MDI patients (group P) arise from a distinct subpopulation, sharing ancestors (founders) with 

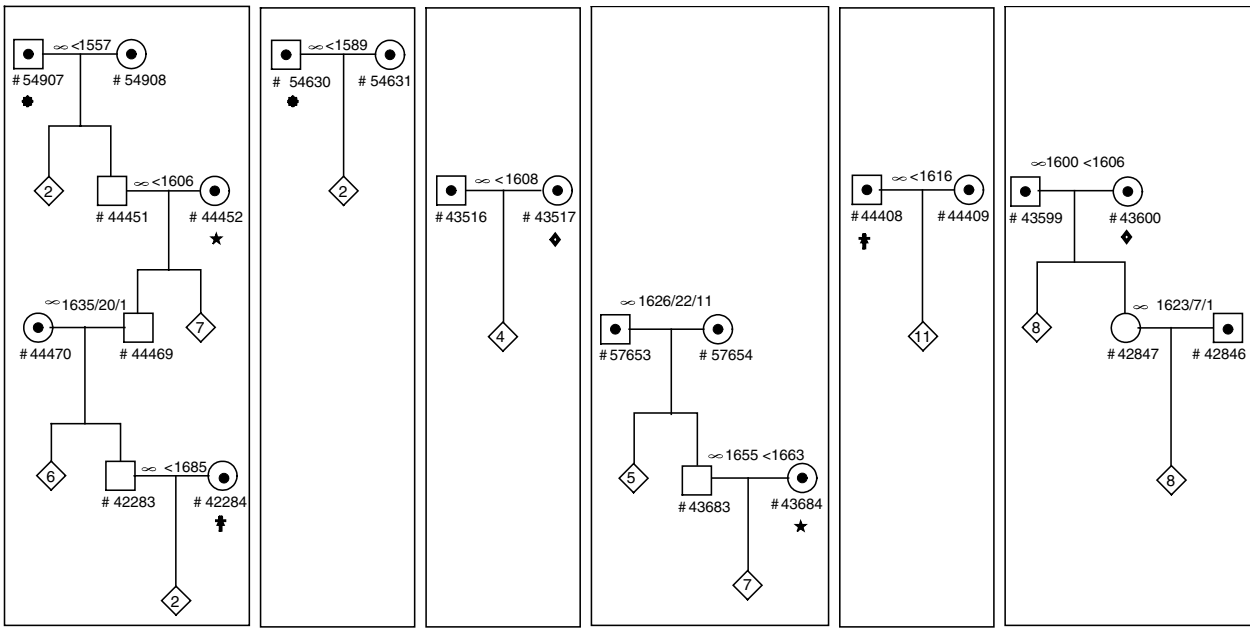

Figure $2 \odot \odot$ Specific founders of $\mathrm{P}$ group; $\infty$, date of marriages; \#, no. of the subjects; $\diamond$, offspring; $\star, \star$, $\star, \bullet$, identical symbols correspond to identical surnames. (Details in text.)

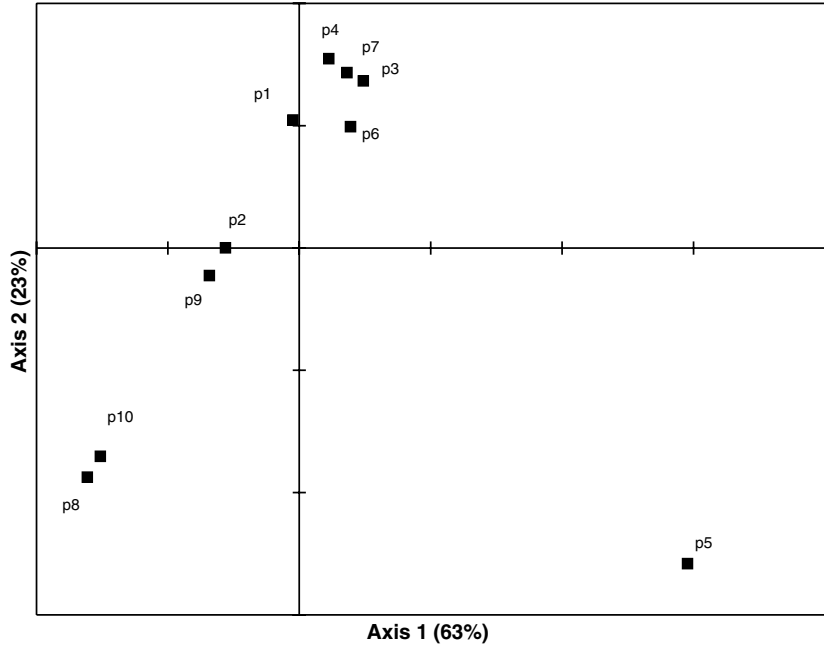

Figure 3 Representation of $P$ individuals according to the genetic contribution of the 17 'specific' founders.

the general S population (as described by the A group), but having also specific founders; control subsets display different characteristics (Tables 2 and 3). Preliminary studies ${ }^{14}$ might confirm this point from an historical and sociological point of view. Ancestors of MDI patients and their relatives had an average lifespan longer than the general population and also the number of their offspring was larger. They tended to occupy higher social positions (mayors, pharmacists, lawyers, small business owners, property owners, etc) whereas most S... inhabitants were agriculture labourers. Their present-day descendants, when interviewed by $\mathrm{CP}$, appeared to be endowed with 'liveliness' expressed by promptitude in thinking and in acting. A moot point is whether this overall apparent increased fitness is due to the hereditary transmission of property

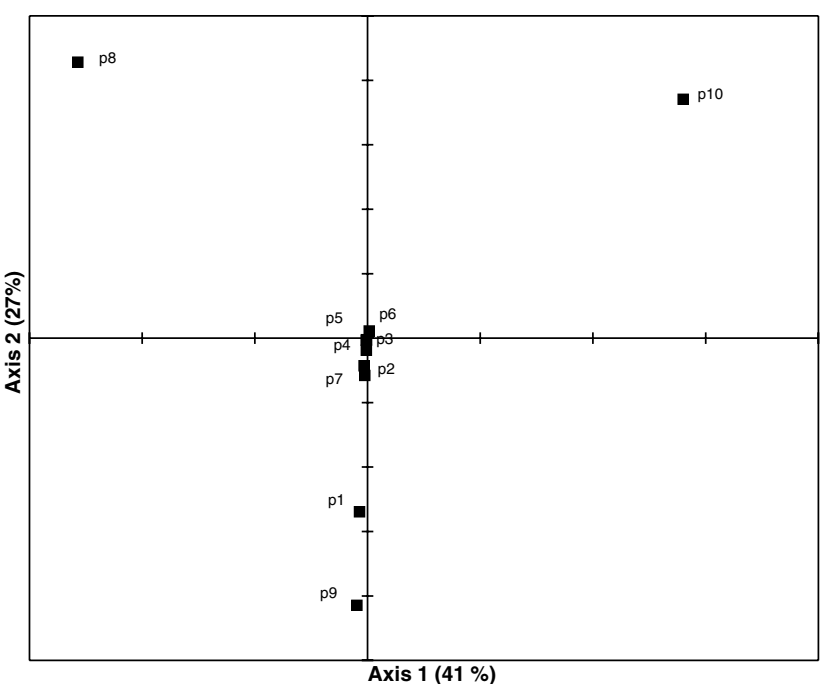

Figure 4 Representation of $P$ individuals according to the genetic contribution of all 673 founders.

and other facilities such as education, or to a pleiotropic effect of an MDI trait. The first explanation implies that a familial nongenetic component extends for multiple generations; this has been documented as unlikely in the Icelandic population, ${ }^{15}$ further work would be needed to test this hypothesis in Calabria. An indication in favour of the latter explanation is the frequency of suicide among these persons, a quite abnormal occurrence within a traditional, catholic population. Another distinctive feature of the MDI subpopulation is the frequency of consanguineous marriages, particularly in comparison with the ancestors of FAD patients. The explanation may be material, because marrying a cousin entailed payment of a tax to the Catholic church, which more affluent persons could afford; it could also be sociological, 
involving different traditions within the subpopulation: anyhow, consanguinity tended to reinforce the homogeneity of the subpopulation. Still another factor might be assortative marriages between persons carrying the same trait. All these features would contribute to the ambiguity of the mode of transmission of any MDI trait, but increase the probability for MDI to be homogenous within the $\mathrm{S}$ population.

Study of the genetic contribution of the founders to the selected MDI probands (Figures 3 and 4) enables us to refine the preceding considerations. Four of the latter (P3, $4,6,7)$ are genetically near from one another in respect of all founders: homogeneity of traits within this subgroup is nonspecific, and probably because of recent coalescence. Two further probands (P2, 5) display globally the same genetic profile, but contribution of the 17 specific founders is different. P8 and P10 are most interesting, because, although they are far from one another and also from the first group in respect of the 'nonspecific' founders, they are very close in respect of the specific founders. To a lesser extent, P9 and P2 are also of interest. There is a high, although hardly measurable, probability for P8 and P10 to share, about 13 generations later, a part of the genome originating from one of the 17 'specific' founders, and for that part to contain any locus involved in the MDI instance that is present in the $S$ population.

Furthermore, the fact that the 17 ancestors are grouped in six founder couples among which two are the most ancient and bear the same surname (Figure 2), allows us to hypothesize that before 1600 they belonged to the same family and therefore reinforces the hypothesis according to which the MDI trait is identical by descent within the $S$ population.

These conclusions could have relevance to endeavours directed towards molecular genetics study of mood disorders, although, naturally, results thus obtained would most probably throw light on a part of the picture only.

\section{Acknowledgements}

This study was supported in part by Assessorato alla Sanità, Regione Calabria, and by Associazione per la Ricerca Neurogenetica-Onlus (ARN). BT was supported by a research grant from Association Française contre les Myopathies. We thank Nicoletta Smirne and
Cinzia Calignano for transcription of public records into the database, and Antonio Rotella for upgrading and maintaining that database. Municipal officials in $N \ldots$ and $S \ldots$, and the parish rector of $S \ldots$ generously helped us in our exploration of the archives under their jurisdiction.

\section{References}

1 Mendlewicz J, Rainer JD: Adoption study supporting genetic transmission in manic-depressive illness. Nature 1977; 268: 327-329.

2 Kelsoe JR, Ginns EI, Egeland JA et al: Re-evaluation of the linkage relationship between chromosome $11 \mathrm{p}$ loci and the gene for bipolar affective disorder in the Old Order Amish. Nature 1989; 342: 238-242.

3 American Psychiatric Association: Descriptive and statistical manual-IV. Washington DC: American Psychiatric association, 1994

4 Foncin JF, Salmon D, Supino-Viterbo V et al: Démence présenile d' Alzheimer transmise dans une famille étendue. Rev Neurol 1985; 141: 194-202.

5 Sherrington R, Rogaev EI, Liang Y et al: Cloning of a gene bearing missense mutations in early-onset familial Alzheimer's disease. Nature 1995; 375: 754-760.

6 Bruni AC, Montesi MP, Manfredi R, Gei G, Ermio C, Caruso G: Un esteso ceppo con probabile psicosi maniaco-depressiva. Riv Psichiatria 1989; 24: 175-181.

7 Bruni AC, Montesi MP, Manfredi R et al: Linkage studies of major affective disorders: The impact of the extension of the pedigrees. Eur Psychiatry 1992; 7: 145-146.

8 Perri C, Ouellette G, Foncin J-F et al: From pedigree to population studies in bipolar disorders. 6th World Congress on Psychiatric Genetics, Bonn, 6-10 October, 1998. Abstract in: Am J Med. Genet (Neuropsychiatric Genetics) 1998; 81: 492.

9 Bruni F. Storia di Serrastretta dalle origini al 1938. Rubettino, Soveria Manelli, 1980.

10 Heyer E, Tremblay M: Variability of the genetic contribution of Québec population founders associated with some deleterious genes. Am J Hum Genet 1995; 56: 970-978.

11 Bruni AC, Montesi MP, Gei G, Ermio C, Rainero I, Foncin J-F: The common origin of FAD in Calabria. In Iqbal K, McLachlan DRC, Winblad B, Wisniewski H (eds): Alzheimer's disease: basic mechanisms, diagnosis and therapeutic strategies. Chichester: John Wiley and Sons, 1991, pp. 451-455.

12 Kraepelin E. Psychiatrie, ein Lehrbuch für Studierenden und Ärtzte, 4th ed., Leipzig: Abel Meiner, 1893.

13 Bellivier F, Laplanche JL, Leboyer M, Feingold J: Serotonine transporter gene and manic depressive illness: an association study: Biol Psychiatry 1997; 41: 750-752.

14 Perri C, De Vito O, Foncin JF, Bruni AC: Correlation between mood disorders and fitness. Am J Med Genet - Neuropsychiatric Genet 2002; 114: 714.

15 Gundmundsson H, Gudbjartson DF, Kong A et al: Inheritance of human longevity in Iceland. Eur J Hum Genet 2000; 8: 743-749. 